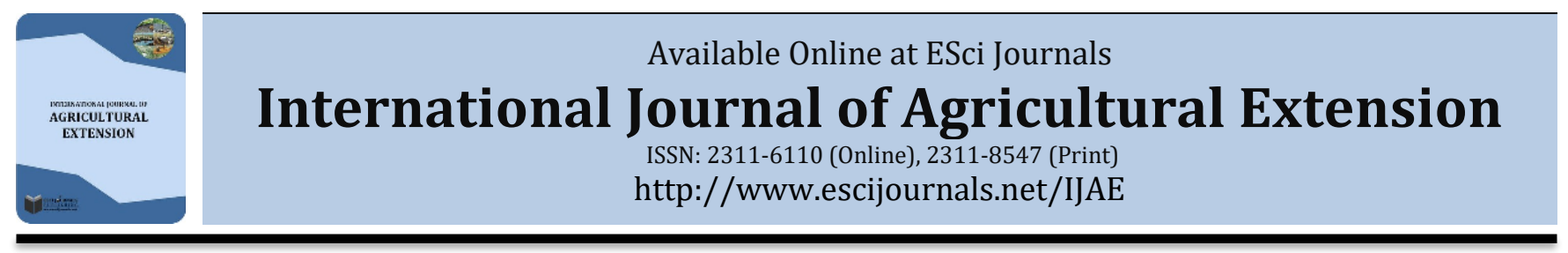

\title{
USABILITY ATTRIBUTES INFLUENCING THE ADOPTION AND USE OF MOBILE APPS FOR DISSEMINATION OF AGRICULTURAL INFORMATION
}

\author{
aJonathan C. Kandagor*, bJason M. Githeko, aArnold M. Opiyo \\ a Department of Crops, Horticulture and Soils, Egerton University, Kenya. \\ b Department of Computer Science, Egerton University, Kenya.
}

\section{A B S T R A C T}

Mobile apps such as social media have friendly attributes and unbiased usage across gender and age; and have become one of the most promising channels for dissemination of agricultural information. The current sources of agricultural information available to farmers do not allow a two-way flow of information and instant feedback. The information disseminated using such channels are generally not customized to specific farmers' needs. Despite the availability of various mobile apps providing agricultural information, the adoption rate is too minimal. The aim of this study was to determine the usability attributes of social media influencing its adoption and use. A semi-structured questionnaire was used to collect data from a sample of 149 respondents. The respondents were selected through purposive sampling technique from a population comprising of farmers, extension staff, lecturers and students enrolled in agricultural courses participating in the Farm Attachment Program of Egerton University. Data collected was analysed using Statistical Packages for Social Sciences (SPSS) and probit regression was used to analyse expected probability of social media adoption. The findings indicate that the main usability attributes of social media are Ease of use, usefulness, credibility, flexibility and Internet availability. Mobile apps being used to disseminate agricultural information should incorporate some of the usability attributes that have significantly influenced the adoption and use of social media to enhance its uptake and use.

Keywords: Social media, e-extension, usability attributes, agricultural apps, mobile apps.

\section{INTRODUCTION}

Access to updated and timely agricultural information and knowledge through mobile devices help farmers make well informed decisions about their agricultural operations (Mwakaje, 2010), which results in higher production and financial benefits (Soriano, 2007). Traditional channels and new technologies have played a key role in diffusing information to rural communities and now have much more potential to improve their agricultural productivity. However, some of these sources of information are inaccurate, limited and untimely. This includes not only to the limited amount of digital content accessible, but also to hardware and software constraints, connectivity costs, reliability and inadequate ICT skills (Jones, 2005). In addition, they lack interactivity, storage, retrieval and sharing features.

\footnotetext{
* Corresponding Author:

Email: Kandagor@egerton.ac.ke

(C) 2018 ESci Journals Publishing. All rights reserved.
}

Santucci (2005) outlined a number of barriers to the use of traditional media which includes inability of the audience to engage in the discussion, lack of rapid feedback as well as replay or repeat of previous programs. Bhattacharjee (2016), suggested that archiving of agricultural information is important in Agricultural Extension and Advisory Services (AESA) to enable users retrieve, share and manage the information as and when needed.

Currently there are some mobile applications provided by both National Government and County Governments being used by farmers in Kenya to access information. These applications include Kenya Plant Health Inspectorate Service (KEPHIS) Maize Variety SMS Service (Irungu et al., 2016) and KEPHIS SMS service for identifying genuine seed sellers (Brugger, 2011). There are other mobile apps provided by private companies for selling and buying agricultural products such as Online exchange (OLX) for selling agricultural products. A study 
by Morwani et al. (2017) found that Mobile banking, OLX, Mkesho and E-extension were the least popular ICT based services for marketing agricultural produce by farmers. The adoption rate of such agricultural mobile applications by various agricultural stakeholders in Kenya has been minimal compared to the rate at which social media is being adopted for general purposes. Cullen (2001) suggested that providing digital content in vernacular language of each community is a key issue in persuading the users of the relative advantage of the technology, thus accelerating the adoption of Internet as a new technology innovation, as well as reducing the difficulty involved in its use.

The traditional channels for agricultural information dissemination to farmers such as the TV, radio, websites, print media and public gatherings have been found to be non-interactive and partially reliable. The information disseminated using these channels are generally not customized to specific farmer needs and in most cases, there is no dedicated expert to respond to farmers queries in addition to poor timing and lack of replay and future reference point. Sharma et al. (2012) found that perceived quality and relevance of the information provided by these channels were highly variable and farmers expressed dissatisfaction with information being transmitted by one-way media and they preferred those sources providing two-way communication where they can put queries and receive responses promptly or when needed.

Farmers are now able to access agricultural resources over the Internet or SMS either through their mobile phones or computers. This has been as a result of evolution of digital technologies which have stimulated dormant economies especially in Africa where there is progressive increase in agricultural productivity due to application of modern communication technologies in agriculture. In addition, TV and radio offers a means to obtain up-to-date information on modern, efficient and cost-effective farming systems that can produce higher yields. However, Kishore \& Gupta (2011) observed that despite televisions being found in most households, they are mostly used for entertainment. On the other hand, radio dissemination of agricultural information is made for a limited number of times a day and given very short air time hence making it difficult for farmers to time it regularly (Mwakaje, 2010), besides using a specific language which some farmers in the country may not understand.
Proper dissemination of agricultural information enhances the fight against poverty and the effort to achieve adequate food production. Kiplang'at (2013) suggested that propagation of relevant information to the farming communities can facilitate their effective adoption of agricultural inputs, decision making on markets and adoption of scientific methods. However imperfect information and high transaction expenses can be major obstacle in the agricultural marketing process.

Social media has transformed how people share information and knowledge in the society and it has enhanced the preservation of indigenous knowledge; its expansion generates new opportunities for different sectors of the economy (Owiny et al., 2014). These sites (WhatsApp, Facebook, Twitter, Instagram and Youtube) have become increasingly popular with the rise of Web 2.0, providing improved teamwork and sharing among users through such applications. A great variety of people use social media both for social and professional purposes; youth, in particular, use these new technologies to create instant communities of practice (Castells et al., 2007). Social media can enhance the promotion of agricultural extension programs through real-time interaction with farmers as well as many other potential agricultural stakeholders that may otherwise not know about extension services through ordinary channels of agricultural extension.

Studies have shown that social media in Kenya is increasingly becoming the major source of information sharing. According to Consumer Barometer with Google 2014/2015, 20\% of Kenyan consumers turn to Social Networks or Social media when looking for local businesses. In addition, Nendo, a Kenyan digital strategy, research and training agency, indicated that the estimated monthly users per social media platform based on smart phone penetration as of September 2017 were as follows: WhatsApp 12 million, Facebook, 7.1 million, Youtube 8 million, Instagram 4million, Twitter 1 million (Bloggers Association of Kenya, 2018). The Communication Authority of Kenya (CAK) attributed the increase of mobile data subscriptions to the continued fall in the price of smart phones costs as well as the wide spread and availability of handets (CAK, 2017). On the other hand, the proliferation of social media has been attributed to the availability of smart phones. Therefore, the growth rate of social media usage is expected to improve significantly. Asur et al. (2011) suggested that 
social media is growing at an explosive rate, with millions of people all over the world generating and sharing content extensively and through their visibility, the trending topics affect the public agenda of the community.

Social media is the most active platform for communication and networking allowing online users to receive latest news updates from various sources. Users can now comment on news stories and be drawn into the conversation. According to Maeve \& Brenner (2013), women are more likely than men to use the social media. Men mostly use social media for economic reasons while women use social media to share personal information, revealing more of their personal lives and they are more vocal, expressive and willing to share. Some of the good examples of social media use in farming include the digital youth who advertise their products through Facebook by posting product photographs, indicating their offer price and giving the location as well as responding to queries from customers and fellow digital farmers (Irungu et al., 2016). A group of dairy farmers from Lessos, Nandi County (Kenya) use WhatsApp to network, train and mentor other dairy farmers (Kioko, 2015). In addition, another group of young farmers in Nyeri, Kenya use a WhatsApp group to share experiences, ask questions and get advice on how to manage insect pests and diseases in their crops as well as market their agricultural produce (Vries, 2016).

Social media is now influencing decision making in Kenya positively both in the private sector and government. There are several instances where social media has been put into action, including the twitter hashtag \#Riomess where Kenyans posted their disappointment with the way the National team was mismanaged by Kenya National Olympic Committee during the RIO 2016 Olympics in Brazil, \#SomeonetellCNN where Kenyans criticized the CNN for calling Kenya a "hotbed of terror" (Janeth, 2015).

However, information on social media platforms suffers from a lack of professional gatekeepers to monitor content. Some users have contravened traditional and societal moral values. It has facilitated the spread of hate speech and rumours in the society. The worst reported misuse of social media is posting and sharing of hate messages along political affiliations and ethnicity (Merab, 2014). Furthermore, sharing of heart breaking news, messages, pornography, images and videos of injured or dead persons as a result of accidents or terror attacks are some of the weaknesses of social media. Some unscrupulous users have used it to solicit money from innocent users; e.g. when some people sold leaked "Kenya Certificate of Secondary Education exams" through WhatsApp to students from various schools. The number of TV viewers and radio listeners is expected to decline significantly as a result of the viewers and listeners getting the information earlier through their social media platforms thus only watch or listen for confirmation of what they had read earlier.

International Standards Organisation (ISO) defined usability as "the extent to which a product can be used by users to achieve specified goals with effectiveness, efficiency and satisfaction in a specified context of use" and this description has been updated in the subsequent directives (Abran et al., 2003). Usability attributes are becoming core aspects of any system development process to improve and enhance system facilities and to satisfy users' demands. Usability confirms if the system is resourceful, effective, safe, easy to learn, easy to use and provide job satisfaction to the users (Dix, 2009). If a system does not have the minimum required usability attributes, the users will definitely leave the system. Literature shows that there has been lack of consensus on the definition of usability. However, usability embraces the four main components of every work situation: user, task, system and environment. Therefore, "usability" can be defined in terms of interaction between user, task and system in the environment (Roger \& Lund, 2011).

Mobile applications can be a very influential tool to help farmers access or share customized information as per their agricultural operations at a time and place of their choice. Thus, identification of those usability attributes that influence the adoption and use of mobile apps is paramount to the successful use of mobile apps by farmers and other stakeholders.

\section{METHODOLOGY}

Study area and sampling procedure: The study was carried out in Baringo and Nakuru Counties in the former Rift Valley province in Kenya. Both counties practice livestock and crop production either commercial or subsistence farming. The two counties were selected because they had been hosting Egerton University agricultural sciences students on Farm Attachment Program under the FarmUP project which is collaboration between Egerton University and the two Counties whereby the students are attached to the 
farmers' farms for at least two months. The sample comprised of women, men and youth above 18 years from the two counties who were associated or linked to FarmUP project.

A sample of 149 respondents was selected through purposive sampling technique from a population of farmers and extension officers from the two counties, agricultural sciences students and lecturers from Egerton University. Purposive sampling was used because the population was small and the respondents were well conversant with the various sources of

\begin{tabular}{lccc}
\hline Groups and County & Total population & Percentage & Sample \\
\hline Nakuru County farmers hosting the students & 439 & 19 & 28 \\
Baringo County farmers hosting the students & 251 & 11 & 16 \\
Extension officers from Nakuru County & 426 & 19 & 28 \\
Extension officers from Baringo County & 293 & 13 & 20 \\
Agricultural Sciences students & 725 & 32 & 48 \\
Agricultural experts (lecturers) & 126 & 6 & 9 \\
Total & 2260 & 100 & 149 \\
\hline
\end{tabular}

Data collection instrument and procedure: A semistructured questionnaire was the main instrument for data collection from the respondents. Before visiting the farmers, extension officers, lecturers and students, appointments were made through mobile phone calls. The instrument was administered through direct interviews and observations on the respondents.

Data analysis: To identify the usability attributes of social media, Principal component analysis was used to reduce the variables and probit regression used to estimate the probability of adoption and use of social media by farmers and other agricultural stakeholders.

$F(x)=\emptyset(x)=\int_{\infty}^{x} \emptyset(z) d z$

Where $\emptyset(z)$ is the normal density function;

$\emptyset(z)=\frac{\exp \left(-2 \frac{2}{2}\right)}{\sqrt{2 \pi}}$

The probit model can be derived from a latent variable model. Let $\mathrm{y} *$ be an unobserved or latent variable determined by,

$Y^{0}=\beta_{0}+\beta_{1} P E O U+\beta_{2} P U+\beta_{3} C R E D+\beta_{4} A W A+$

$\beta_{5}$ FLEX $+\beta_{6}$ INTER $+\varepsilon$

PEOU - Perceived ease of use

PU - Perceived usefulness

CRED - Perceived credibility

AWAR - Perceived awareness agricultural information, in addition to limited resources available.

The sample size was computed based on the formula proposed by Nassiuma (2000);

$$
n=\frac{N C^{2}}{C^{2}+(N-1) e^{2}}
$$

Where $n=$ sample size, $\mathrm{N}=$ Total number of farmers, extension officers, agricultural students and lecturers attached to FarmUP project of Egerton university, $\mathrm{C}=$ Coefficient of variation and $\mathrm{e}=\mathrm{Standard}$ error. For this study $\mathrm{N}=2260, \mathrm{C}=25 \%$ and $\mathrm{e}=2 \%$.

FLEX - Perceived flexibility

NTER - Perceived internet availability

RESULTS AND DISCUSSION

Socio-economic characteristics of the respondents:

The results shown on Table 1 indicate that $28.9 \%$ of the respondents were from Baringo County and the remaining $71.1 \%$ were from Nakuru County. Majority of the respondents were from Nakuru County because the agricultural students and lecturers were from Egerton University in addition to farmers and the extension officers. Results further show that $73.2 \%$ of the respondents were male and $26.8 \%$ were female. This was due to the fact that majority of the household heads were male especially the farmers; and most of the female extension officers were unwilling to fill the questionnaires. In addition, traditional cultures and values could be associated with the higher percentage of male respondents whereby male were the house heads and the sole decision maker.

The results further indicate that $41 \%$ of the respondents were aged between 18-28 years. This was perhaps because $32.2 \%$ of the respondents were agricultural sciences students from Egerton University and majority of the newly employed agricultural officers by Baringo and Nakuru Counties were youthful, who were assigned the responsibility of filling in the questionnaires by their senior older extension officers. In addition, most of the older farmers preferred their children to assist them in 
filling in the questionnaires. The results also show that $11 \%$ of the respondents were over fifty (50) years. This implied that $89 \%$ of the respondents were below 50 years; therefore, majority of them can access agricultural information through social media such as WhatsApp, Facebook and Twitter among others. In terms of education level, most of the respondents had received tertiary education $(82.6 \%)$ while the least proportion $(0.7 \%)$ of the respondents had no formal education. In addition, the results show that $3.4 \%$ had primary education; $12 \%$ had secondary education while $1.3 \%$ had attended adult literacy education. This means that $98 \%$ of the respondents had attended formal education. This is very important in terms of technical skills required to use mobile applications in decision making and accessing agricultural information online as well providing critical thinking which enables agricultural stakeholders to be able to examine an issue by breaking it down, and evaluating it in a conscious manner, while providing substantiation to support their opinions.
Nelson \& Phelps (1966) suggested that education enhances one's ability to receive, decode, and understand information, and that information processing and interpretation is important for performing or learning to perform many jobs.

Farming is the major source of income for majority of the respondents (43.6\%), since even some of those on formal employment and students still practice farming as an alternative source of income. Formal employment was ranked as the second (34.4\%) source of income. About $13.3 \%$ of the respondents relied on remittances from relatives and friends as their source of income; this could be attributed to the presence of university students who rely mostly on their parents and relatives for their income. Casual labour received $2^{\text {nd }}$ least $(7.2 \%)$ as the source of income while trade received the least percentage $(1.5 \%)$ and could be credited to the fact that majority of the respondents practiced farming as their other source of income instead of venturing into other non-agricultural enterprises.

Table1. Socio-economic characteristics of the respondents $(n=149)$.

\begin{tabular}{|c|c|c|}
\hline Demographic Characteristics & Frequency & Percent \\
\hline \multicolumn{3}{|c|}{ County of origin } \\
\hline Baringo & 43 & 28.9 \\
\hline Nakuru & 106 & 71.1 \\
\hline \multicolumn{3}{|c|}{ Gender } \\
\hline Male & 109 & 73.2 \\
\hline Female & 40 & 26.8 \\
\hline \multicolumn{3}{|c|}{ Age } \\
\hline $18-28$ & 61 & 41 \\
\hline $29-39$ & 32 & 21.5 \\
\hline $40-50$ & 40 & 26.8 \\
\hline Above 50 years & 16 & 10.7 \\
\hline \multicolumn{3}{|c|}{ Education Level } \\
\hline None & 1 & 0.7 \\
\hline Primary & 5 & 3.4 \\
\hline Secondary & 18 & 12.0 \\
\hline Tertiary & 123 & 82.6 \\
\hline Adult literacy & 2 & 1.3 \\
\hline \multicolumn{3}{|c|}{ Primary source of income } \\
\hline Formal employment & 67 & 34.4 \\
\hline Trade & 3 & 1.5 \\
\hline Farming & 85 & 43.6 \\
\hline Remittances & 26 & 13.3 \\
\hline Casual labour & 14 & 7.2 \\
\hline
\end{tabular}


Respondents possessing ICT skills to operate smart phone per occupation and gender: The results per category as shown in Table 2 indicate that $94 \%$ of the students, $82 \%$ of farmers, $100 \%$ of lecturers and $95 \%$ of the extension officers had basic ICT skills to operate a smart phone. These findings could be based on the fact that lecturers, students and extension officers were more exposed to the ICT technologies than the farmers. The results further show that over $75 \%$ of the respondents from either gender possess basic ICT skills. Much of our digital activities are now converging around portable devices and smart phones continue to push Internet penetration worldwide. Furthermore, introduction of online services by the Kenya Government and private sector has encouraged the citizens to acquire basic ICT skills. With that level of basic ICT skills to operate smart phones by the agricultural stakeholders, it makes it possible to disseminate agricultural information through smart phones in any format to the targeted consumers.

Usability attributes of social media influencing its adoption and use in dissemination of agricultural information: Table 3 presents the results of a probit regression on usability attributes influencing the adoption and use of social media for dissemination of agricultural information. The baseline probability of using social media to disseminate information is 0.94 implying that taking any agricultural stakeholder at random, there is a $94 \%$ chance of having an internet enabled phone and use it to disseminate information.

Table 2. Cross tabulation between occupation, respondents with ICT skills and gender.

\begin{tabular}{lcccccc}
\hline Gender of Head of Household & \multicolumn{2}{c}{ Male } & \multicolumn{2}{c}{ Female } & \multicolumn{2}{c}{ Total } \\
\hline Occupation /ICT skills; (F=Frequency) & $\mathrm{F}$ & $\%$ & $\mathrm{~F}$ & $\%$ & $\mathrm{~F}$ & $\%$ \\
Students $\quad(\mathrm{n}=48)$ & 35 & 95 & 10 & 91 & 45 & 94 \\
Farmers $\quad(\mathrm{n}=44)$ & 24 & 86 & 12 & 75 & 36 & 82 \\
Lecturers $\quad(\mathrm{n}=9)$ & 8 & 100 & 1 & 100 & 9 & 100 \\
Extension officers $(\mathrm{n}=48)$ & 35 & 97 & 11 & 92 & 46 & 96 \\
\hline
\end{tabular}

Table 3. A probit estimate on usability attributes influencing adoption and usage of social media.

\begin{tabular}{lccc}
\hline Variable & Dy/dx & Standard Error & P $>\mathrm{z}$ \\
\hline Ease of use score & 0.031 & $-0.800^{*}$ & -0.087 \\
Usefulness score & 0.042 & $2.480^{* *}$ & 0.022 \\
Flexibility score & 0.004 & $1.770^{* * *}$ & -0.001 \\
Credibility score & 0.022 & $0.920^{* *}$ & -0.022 \\
Awareness score & 0.025 & $-0.800^{*}$ & -0.069 \\
Self-efficacy score & 0.034 & -2.860 & -0.164 \\
Access internet score & 0.003 & $-0.060^{* * *}$ & -0.006 \\
Gender & 0.041 & -1.800 & -0.155 \\
Age & -0.001 & 0.001 & 0.418 \\
\hline
\end{tabular}

Note: ${ }^{*}, * *, * * *$ represents significance levels at $10 \%, 5 \%$ and $1 \%$ respectively.

The results show that agricultural stakeholders' perception towards the ease of use of ICT tools in disseminating agricultural information had a positive influence on the usage of social media. This implies that as the stakeholders' confidence towards using ICT tools increased, they were statistically influenced to adopt social media $(\mathrm{dy} / \mathrm{dx}=0.031, \mathrm{p}<0.1)$. This shows that increasing the stakeholders' usability of mobile apps would lead to increased usage of social media. That is, the more stakeholders' find it easy to use social media, the more they are likely to adopt it as a platform for disseminating agricultural information. Users tend to be drawn towards using easily understandable systems as opposed to complex systems.

Perceived ease of use is associated with a positive relationship with the use of mobile banking (Alsamydai, 2016); and can also contribute in an instrumental way in improving a person's performance, because the user will have to deploy less effort with a technology which is easy to use. 
The results further reveal that the perception towards usefulness of ICT tools significantly influences increased use of social media towards dissemination of agricultural information $(\mathrm{dy} / \mathrm{dx}=0.042, \mathrm{p}<0.05)$. This is true because smallholder farmers adopt technologies that they perceive to be more useful to their lives. As the degree of usefulness of a technology increases, the more the users adopt the technology from which they derive the use. Ma et al., (2005), found that perceived usefulness of computer technology had a direct significant effect on user's intention to use it. Previous studies also have suggested that perceived usefulness had positive effects on attitudes, behavioral intentions, and user acceptance of a given technology. Among the main variables of TAM; perceived ease of use and perceived usefulness, studies have found perceived usefulness to have the strongest influence.

In comparison to users and non-users of social media, users found social media to be more flexible as opposed to their counterparts which was statistically significant (dy/dx $=0.004, p<0.01)$. Flexibility of a technology is one of the main user attributes that leads to increased demand for its usage. The fact that a technology can be used for several activities leads to its increased demand, also users' perception that they can use a technology with limited restrictions and supervision enhances its adoption and usage. It is therefore not surprising that farmers would feel the same towards flexibility of social media. This is because; social media can disseminate a wide range of information while providing a platform for feedback instantaneously. This means that the more farmers perceive social media to be flexible, the more they will use it to disseminate the relevant agricultural information. Flexibility of the social media is seen as a source of some comparative advantage to the farmers since information is the key towards unlocking agricultural business opportunities. By virtue of being flexible, social media bring a wider variety of benefits to the consumer than they would anticipate.

Results further revealed credibility of the source of information to positively influence adoption of social media as a means of disseminating agricultural information ( $d y / d x=0.022, p<0.05)$. This is expected as users will use more of an ICT technology that gives them credible information or they trust the information sources. While ICT platforms may disseminate any information whether wrong or correct, the fact that the more information disseminated is true and helpful to farmers, builds on their ability to trust the sources of information. Hence, the virtue of credible information implies that more and more farmers would be willing to disseminate the information to their friends in the farming community. The more the farmers trust the information sources, the more they are likely to disseminate it using social media. Ahn \& Ha (2011), noticed that individuals' perceptions on source credibility of a received tweet play a key role in their information sharing behavior via the perceived level of usefulness of the information. In addition, Erkan and Evans (2016) confirmed that quality and credibility among other factors are the main factors of electronic word of mouth (eWOM) in social media that influence consumers' purchase intentions.

The results also show that farmers awareness of information and various social media platforms increases their likelihoods of disseminating the information through social media $(\mathrm{dy} / \mathrm{dx}=0.025$, $\mathrm{p}<0.1$ ). Although some social media outlets are complex and hard to use, some ICT tools make these platforms more user friendly. The more a consumer is aware of the existence of a certain platform and its usefulness in their businesses, the more they are likely to incorporate such a platform as a critical tool for decision making. Therefore, farmers who are aware of the existence of social media platforms are more likely to use the platforms in disseminating agricultural information. This implies that increasing the level of awareness to the existence of social media platform and its economic benefits, not only increases its users but also the amount of information being disseminated through such a platform. This is expected to be true since human beings are social in nature and would connect with their counterparts through a platform that they perceive to be friendlier and are aware of how to use it.

Lastly, the results reveal that access to the Internet increases the chance to disseminate agricultural information through social media among the farmers (dy/dx $=0.003, p<0.01)$. This is expected since despite the existence of interactive social media platforms that do not require usage of the Internet, their adoption rate has been so minimal.

Access to the Internet increases the opportunities to access better information as well as the ability to distribute the information. The Internet may be perceived by farmers as a collection of many relevant materials and hence access to such materials increases 
the chance to use social media in disseminating agricultural information. Consumers of information are powered by the quality of information they receive, high speed Internet connectivity to facilitate access to such information databank and authenticity of the information accessed. Also, the Internet provides an avenue for comparing and benchmarking the information from different outlets. Therefore, access to the Internet by agricultural stakeholders increases the likelihood to use social media in its dissemination of agricultural information.

\section{CONCLUSIONS AND RECOMMENDATIONS}

Usability attributes play a central role in the adoption and use of mobile apps for dissemination of agricultural information to the targeted farmers. Usability enhances user's confidence towards the use of agricultural mobile apps since they do not have to put more effort to learn and use the apps in accessing or sharing information. In order to facilitate rapid agricultural information and knowledge transfer to a wider population, mobile apps being used to disseminate agricultural information should incorporate some of the usability attributes that seem to have positively and significantly influenced the adoption of social media. Access to timely agricultural information through mobile apps helps farmers improve their agricultural production, marketing hence improving their livelihoods. The main usability attributes of social media which seem to have positively and significantly influenced the adoption and use of social media were ease of use, usefulness, flexibility, credibility, awareness and internet access.

Therefore, software developers designing agricultural apps should incorporate usability attributes to allow farmers use the apps without struggling to learn how to use them or to access information. Any information to be disseminated through mobile apps should have to be authenticated to avoid sharing misleading or incorrect information. This is because once information has been shared online, it will not be possible to retrieve it for correction. Furthermore, for successful utilization of online agricultural information, there should be awareness creation among the various agricultural stakeholders and provision of training where necessary.

\section{ACKNOWLEDGEMENT}

I would like to sincerely thank Prof. Jason M. Githeko, Dr. Arnold M. Opiyo and Prof. Nancy W. Mungai for their guidance, help and encouragement through this work. Also, I would take this opportunity to thank Egerton
University and RUFORUM for the funding. Equally, I appreciate the contribution of respondents who agreed to fill in the study questionnaire.

\section{REFERENCES}

Abran, A., Khelifi, A. \& Suryn, W. (2003). Usability Meanings and Interpretations in ISO Standards, 325-338.

Ahn, J. \& Ha, S. (2011). Why are you sharing others' tweets?: The Impact of Argument Quality and Source Credibility on Information Sharing Behavior. In Proceedings. 4. ICIS.

Alsamydai, M. J. (2014). Adaptation of the Technology Acceptance Model (TAM) to the Use of Mobile Banking Services. Journal of International Review of Management and Business Research, 3(4), 2019.

Asur, S., Huberman, B. A., Szabo, G. \& Wang, C. (2011). Trends in Social Media: Persistence and Decay. Proceedings of the 5th International AAAI Conference on Weblogs and Social Media (ICWSM'11), 5(4), 434-437.

Bloggers Association of Kenya. (2018). State of the Internet in Kenya 2017. Retrieved from https://www.ifree.co.ke.

Bhattacharjee, S. \& Raj, S. (2016). Social media : Shaping the future of agricultural extension and advisory services. GFRAS interest group on ICT4RAS discussion paper, GFRAS: Lindau, Switzerland, 9.

Brugger, F. (2011). Mobile Applications in Agriculture. Syngenta Foundation. Retrieved from http://www.gsma.com.

Castells, M., Fernández-Ardèvol, M., Qiu, J. L. \& Sey, A. (2007). Mobile Communication and Society: A Global Perspective. The MIT Press.

Communication Authority of Kenya. (2017). Fourth quarter sector statistics report for the financial year 2016/2017 (April-June 2017) (Vol. 2017).

Consumer Barometer with Google. (2015). The Online \& Multiscreen World (KE). Retrieved 7-3- 2018.

Cullen, R. (2001). Addressing the digital divide. The Electronic Library, 25(5), 311-320.

Dix, A. (2009). Human-computer interaction. In Human Computer Interaction Handbook: Fundamentals, Evolving Technologies ... (pp. 1327-1331). Springer US.

Evans, I. \& Evans, C. (2016). The influence of eWOM in social media on consumers' purchase intentions: An extended approach to information adoption. In 
Computers in Human Behavior, 61, 47-55.

Irungu, K. R. G., Mbugua, D. \& Muia, J. (2016). East African Agricultural and Forestry Information and communication technologies (ICTs ) attract youth into profitable agriculture in Kenya. East African Agricultural and Forestry Journal, 81(1), 24-33.

Janeth, J. (2015). \#SomeoneTellCNN: CNN reporter calls Kenya a terror hotbed [Blog post]. Retrieved September 16, 2016,

Jones, M. (2005). CTA Annual Report 2004. CTA, Wageningen, The Netherlands.

Kioko, L. (2015). Kenyan Smallholder Farmers take to digital platforms to get Farming Tips. Retrieved January 30, 2018,

Kiplang'at, J. (2013). An analysis of the opportunities for information technology in improving access, transfer and the use of agricultural information in the rural areas of Kenya. Emerald, 20(2), 115-128.

Kishore, D. \& Gupta, V. (2011). ICTs for Agricultural Extension: A Study in the Indian Himalayan Region. The Electronic Journal on Information Systems in Developing Countries, 48(3), 1-12.

Ma, W. W., Andersson, R. \& Streith, K. (2005). Examining user acceptance of computer technology: an empirical study of student teachers. Journal of Computer Assisted Learning, 21(6), 387-395.

Maeve, D. \& Brenner, J. (2013). The Demographics of Social Media Users - 2012. Retrieved January 30, 2018,

Merab, E. (2014). How freedom with minimal social control fans Kenya's digital hatred. Retrieved September 12, 2016.

Morwani, D. N., Ombati, J. M. \& Ngesa, F. U. (2017). Relationship between level of education of farmers and use of information and communication technologies in marketing of farm produce by small scale farmers in Manga subcounty Kenya. International Journal of Scientific \& Technology Research, 6(2).

Mwakaje, A. G. (2010). Information and Communication Technology for Rural Farmers Market Access in Tanzania. Journal of Information Technology Impact, 10(1), 25-34.

Nelson, R. R. \& Phelps, E. S. (1966). Investment in Humans, Technological Diffusion and Economic Growth. The American Economic Review, 56(1), 69-75.

Owiny, S. A., Mehta, K. \& Maretzki, A. N. (2014). The Use of Social Media Technologies to Create, Preserve , and Disseminate Indigenous Knowledge and Skills to Communities in East Africa, 8, 234-247.

Roger, B. \& Lund, H. (2011). Usability and usefulness evaluation: an experiment on the DTU Digital Library (Thesis). By Bararunyeretse Roger Supervisor: Haakon Lund The Royal School of Library and Information Science.

Santucci, F. M. (2005). Strategic Communication for Rural Development. Electronic Media, (July), 128.

Sharma, M., Kaur, G. \& Gill, M. S. (2012). Use of Information and Communication Technology in Agriculture by Farmers of District Kapurthala. Journal of Krishi Vigyan, 1.

Soriano, C. R. R. (2007). Exploring the ICT and Rural Poverty Reduction Link : Community Telecenters and Rural Livelihoods in Wu ' an , China 1. Electronic Journal of Information Systems in Developing Countries, 32(1), 1-15.

Vries, E. D. (2016). Are you on a farmers' WhatsApp group? It is my easy way to network. Retrieved December 5, 2016, 